\title{
Sample Recovery from Cell Culture, Not Otherwise Specified
}

National Cancer Institute

\section{Source}

National Cancer Institute. Sample Recovery from Cell Culture, Not Otherwise Specified. NCI Thesaurus. Code C112944.

A cell culture sample collection process that is not otherwise specified. 